\title{
Residual dormant cancer stem-cell foci are responsible for tumor relapse after antiangiogenic metronomic therapy in hepatocellular carcinoma xenografts
}

\author{
Ines Martin-Padura ${ }^{*, 1}$, Paola Marighetti ${ }^{*, 1}$, Alice Agliano ${ }^{1,2}$, Federico Colombo ${ }^{3}$, Leyre Larzabal ${ }^{2}$, Miriam Redrado ${ }^{2}$,
} Anne-Marie Bleau ${ }^{2}$, Celia Prior ${ }^{2}$, Francesco Bertolini ${ }^{\dagger, 1}$ and Alfonso Calvo ${ }^{*, \dagger, 2}$

Hepatocellular carcinoma (HCC) is the fifth most common solid tumor and the third leading cause of cancer-related deaths. Currently available chemotherapeutic options are not curative due in part to tumor resistance to conventional therapies. We generated orthotopic HCC mouse models in immunodeficient NOD/SCID/IL2r $\gamma$ null mice by injection of human alpha-feto protein (hAFP)- and/or luciferase-expressing HCC cell lines and primary cells from patients, where tumor growth and spread can be accurately monitored in a non-invasive way. In this model, low-dose metronomic administration of cyclophosphamide (LDM-CTX) caused complete regression of the tumor mass. A significant increase in survival $(P<0.0001)$, reduced aberrant angiogenesis and hyperproliferation, and decrease in the number of circulating tumor cells were found in LDM-CTX-treated animals, in comparison with untreated mice. Co-administration of LDM-CTX with anti-VEGF therapy further improved the therapeutic efficacy. However, the presence of residual circulating hAFP levels suggested that some tumor cells were still present in livers of treated mice. Immunohistochemistry revealed that those cells had a hAFP + /CD13 + /PCNA - phenotype, suggesting that they were dormant cancer stem cells (CSC). Indeed, discontinuation of therapy resulted in tumor regrowth. Moreover, in-vitro LDM-CTX treatment reduced hepatosphere formation in both number and size, and the resulting spheres were enriched in CD13 + cells indicating that these cells were particularly resistant to therapy. Co-treatment of the CD13-targeting drug, bestatin, with LDM-CTX leads to slower tumor growth and a decreased tumor volume. Therefore, combining a CD13 inhibitor, which targets the CSClike population, with LDM-CTX chemotherapy may be used to eradicate minimal residual disease and improve the treatment of liver cancer.

Laboratory Investigation (2012) 92, 952-966; doi:10.1038/labinvest.2012.65; published online 30 April 2012

KEYWORDS: angiogenesis; cancer stem cells; hepatocellular carcinoma; metronomic chemotherapy; NSG; xenograft

Hepatocellular carcinoma (HCC) is the fifth most common cancer in the world and one of the few malignancies with an increasing incidence in United States and Europe. In developing countries, HCC often comes to medical attention when tumors are at an advanced stage and curative therapies are of limited benefit. On the other hand, in developed countries, at-risk populations (individuals with hepatitis virus B or C and alcohol-induced liver disease) are usually under closer surveillance and HCC is often detected when tumors are at early stage, which makes treatment more likely to be successful. ${ }^{1}$ However, currently available chemotherapeutic options are not effective because HCC is frequently resistant to conventional chemotherapy and because the use of toxic conventional maximum tolerated dose (MTD) chemotherapy is difficult, due to the associated liver dysfunction often found in HCC patients. ${ }^{2}$ Novel therapeutic regimens are clearly needed but such regimens require the development of new accurate preclinical models of HCC.

In recent years, there has been an exponential increase in our understanding of the molecular alterations occurring in

\footnotetext{
${ }^{1}$ Laboratory of Hematology-Oncology, European Institute of Oncology, Milan, Italy; ${ }^{2}$ Laboratory of Novel Therapeutic Targets, Oncology Division, CIMA of the University of Navarra, Pamplona, Spain and ${ }^{3}$ Laboratory of Cytometry and Hepatology, Fondazione Ospedale Maggiore Policlinico, Milan, Italy

Correspondence: Dr A Calvo, PhD, Laboratory of Novel Therapeutic Targets, Oncology Division, CIMA of the University of Navarra, Pamplona 31008 , Spain.

E-mail: acalvo@unav.es

*These authors contributed equally to this work.

†These authors shared senior authorship.
} 
HCC. Perhaps, the strongest aberrant pathways hyperactivated in HCC are related to angiogenesis. ${ }^{3}$ Studies have shown that long-term low-dose metronomic (LDM) administration of some conventional chemotherapy drugs is able to block endothelial cell repair and tumor angiogenesis. ${ }^{4}$ The antitumor effect elicited by this schedule appears to be superior in terms of survival time compared with conventional therapy, particularly in preclinical models. ${ }^{5,6}$ Cyclophosphamide (CTX) is an alkylating agent that needs hepatic cytochrome P450-catalysed metabolism to attain cytotoxic activity. ${ }^{7}$ CTX has been widely used in metronomic schedules and has demonstrated antiangiogenic effects. ${ }^{8}$ This evidence suggests that metronomic CTX can act both as an antiangiogenic agent and as a cytotoxic drug for cancer cells.

Recent studies have suggested that one of the causes for the high resistance of HCC to therapies is likely due to the presence of cancer stem cells (CSC). The CSC hypothesis states that CSC are responsible not only for tumor initiation, but also for generation of metastasis and local recurrence after therapy. ${ }^{9,10}$ Current definitions of CSC are based only on functional and phenotypic properties. CSC are described as a small population of undifferentiated cells and are generally characterized by self-renewal, through asymmetrical cell division, 'multipotency' or the ability to produce progeny in at least two lineages, long-term tissue reconstitution and serial transplantability. ${ }^{11,12}$ In studies of HCC, the side population fraction, ${ }^{13}$ or cells expressing CD133, CD $44,{ }^{14}$ CD90, ${ }^{15,16}$ and epithelial cell adhesion molecules ${ }^{17}$ are considered as the CSC population. Recently, it has been demonstrated that CD13 is a marker for semiquiescent CSC, and CD13 expression in conjunction with CD133 and CD90 is associated with a more immature stem-like and dormant cell population. ${ }^{16}$

Based on this information, we hypothesized that metronomic treatment of HCC would target CSC leading to effective tumor shrinkage. A possible effect of antiangiogenic therapies could be the disruption of the CSC niche, ${ }^{18}$ thus inducing changes that would sensitize CSC to the cytotoxic effects of CTX. Combination of LDM-CTX with other antiangiogenic agents, such as an anti-VEGF blocking antibody and additional treatments targeting CSC, such as a CD13 inhibitor, could be of help in the design of new therapeutic strategies for a future radical cure for liver cancer.

To study these issues, we developed a new orthotopic model of HCC in NOD/SCID/IL2r $\gamma$ null mice, where tumor growth was monitored with non-invasive techniques. We found that metronomic administration of CTX eradicated the tumor mass eliciting an antiangiogenic response and that anti-VEGF therapy produced an additional antitumor effect. More importantly, we show that this treatment targets CSC, although a residual population of dormant $\mathrm{CD} 13+1$ hAFP + /PCNA - cells could be found in the livers of treated mice. Targeting $\mathrm{CD} 13+$ cells with bestatin had a potent inhibitory effect on tumor growth and elicited a synergistic antitumor response in combination with LDM-CTX. This study underscores the effectiveness of metronomic CTX in treating HCC and suggests that anti-CD13-based therapies and CSC-targeting drugs should be used to eradicate minimal residual disease.

\section{MATERIALS AND METHODS Cells Lines and Cell Cultures}

The human HCC cell lines PLC/PRF-5, HepG2, HEP 3B2.17, SNU-387, and SNU-475 (from American Tissue Type Collection, Manassas, VA) were cultured following the cell bank indications. The HuH-7 human HCC cell line was obtained from the Japanese Cancer Research bank (Tokyo, Japan) and maintained in Dulbecco's modified Eagle's medium with high glucose (EuroClone, Milan, Italy) supplemented with $10 \%$ heat-inactivated FCS (Gibco-Invitrogen, Life Technologies, Carlsbad, CA, USA).

Primary cells were isolated and culture stabilized as described. ${ }^{20}$ Briefly, liver tumor tissue specimens were collected from three patients who underwent hepatectomy, with Institutional Review Board approval and informed consent. Fresh tumors were minced and incubated with Liberase ${ }^{\mathrm{TM}}$ (Roche Diagnostics, Indianapolis, IN, USA) for 5-10 min at $37^{\circ} \mathrm{C}$. The cell suspensions were then washed, filtered through a $40-\mu \mathrm{m}$ cell strainer, seeded onto collagen-coated Petri dishes and cultured with IMDM supplemented with $20 \%$ FBS and $1 \%$ non-essential amino acids (EuroClone) as described elsewhere. ${ }^{19}$

The amphopack-293 packaging cell line (Clontech) was transfected with $\mathrm{pSFG}_{\mathrm{NES}} \mathrm{TGL}$ purified plasmid, kindly donated by Dr Ponomarev (Memorial Sloan Kettering, NY). Transfection was performed using Lipofectamine ${ }^{\mathrm{TM}} 2000$ (Invitrogen, Carlsbad, CA, USA) according to manufacturer's protocol. Culture supernatant containing virus and $7.5 \mu \mathrm{g} / \mathrm{ml}$ Polybrene (hexadimethrine bromide; Sigma, St Louis, MO, USA) were added in two different 4-h cycles to the HuH-7 cells. The plasmid $\mathrm{pSFG}_{\mathrm{NES}} \mathrm{TGL}$ is characterized by the presence of green fluorescent protein (GFP), luciferase, and thymidine kinase genes fused together. By sorting GFP + HuH-7 cells, it is possible to isolate infected cells. The luciferase gene allows for the in vivo detection of cells by luminometry.

\section{Hepatospheres and Time-Lapse Microscopy}

HCC cells were trypsinized, resuspended in PBS and filtered though a $100-\mu \mathrm{m}$ and a $40-\mu \mathrm{m}$ mesh. Cell suspensions $\left(5 \times 10^{5}\right.$ cells $/ \mathrm{ml}$ ) were then labeled with PKH26 (Sigma; $10^{-7} \mathrm{M}, 5 \mathrm{~min}$ ) following manufacturer's instructions. Labeled cells were seeded in plastic flasks and cultured in complete medium. After 7 days, cells were trypsinized, filtered, and sorted for PKH staining with a FACS VantageSE flow cytometer (BD) to yield $\mathrm{PKH}^{+}$and $\mathrm{PKH}^{-}$cells. ${ }^{20} \mathrm{PKH}^{+ \text {high }}$ cells were then plated $(40000$ cells $/ \mathrm{ml})$ in suspension in polyhema (Sigma) coated ultraslow attachment plates (Falcon) in sphere culture medium, which consisted of DMEM (EuroClone) supplemented with $10 \mathrm{mg} / \mathrm{l}$ insulin (Sigma), 
$7.5 \mathrm{mg} / \mathrm{l}$ hydrocortisone (Wako Pure Chemical Industries Ltd, Osaka, Japan), B27 (Invitrogen) $50 \mathrm{~g} / \mathrm{l}$ epidermal growth factor (Biomedical Technologies, Stoughton, MA, USA), $60 \mathrm{mg} / \mathrm{l}$ proline (Wako Pure Chemical Industries Ltd.), $50 \mathrm{~g} / \mathrm{l}$ linoleic acid (Sigma), $0.1 \mu \mathrm{M} \mathrm{CuSO}_{4} 5 \mathrm{H}_{2} \mathrm{O}, 3 \mu \mathrm{g} / \mathrm{l} \mathrm{H}_{2} \mathrm{SeO}_{3}$, $50 \mathrm{pM} \mathrm{ZnSO}{ }_{4} \quad 7 \mathrm{H}_{2} \mathrm{O}, 58.8 \mathrm{mg} / \mathrm{l}$ penicillin, and $100 \mathrm{mg} / \mathrm{l}$ streptomycin. Hepatospheres were collected after 6-8 days and mechanically dissociated. For the serial passage experiment, 5000 cells from disaggregated hepatospheres were plated in 24 multiwell plates and, after 6 days, disaggregated and replated again at the same density. Time-lapse experiments were conducted in a ScanR Olympus-microscope IX81 in an Evotech incubator to maintain $37^{\circ} \mathrm{C}, 5 \% \mathrm{CO}_{2}$, and controlled humidity. Images were captured with an ORCA from Hamamatsu Photonics (Hamamatsu, Japan).

\section{Mice and Orthotopic Liver Implantation}

NOD.cg-Prkdc $c^{\text {scid }} I l 2 r g^{\text {tm } 1 \text { Wjll. }}$ (NSG) mice were kindly donated by Dr L Shultz and bred and housed at Charles River Laboratories (Calco, Italy). Experiments involving animals were carried out in the animal facilities at IFOM-IEO campus (Milan, Italy) and CIMA of the University of Navarra (Pamplona, Spain). All procedures were carried out in accordance with national and international laws and policies.

The male animals used were 6-10 weeks old. Aseptic conditions under a laminar flow hood were used throughout the surgical procedure. Mice were anesthetized with $2.5 \%$ 2-2-2-tribromoethanol (Avertin; Sigma), and laid on their back. A $0.5-\mathrm{cm}$ transverse incision was made through the skin and the peritoneum of the upper abdomen. The median lobe of the liver was exposed by applying gentle pressure on the abdomen and a $10^{5}$ single-cell suspension in $10 \mu \mathrm{l}$ was injected into the subsera of the liver using a Hamilton syringe. Then, the peritoneum and the skin were sewn.

Tumor growth was assessed weekly by detection of human alpha-feto protein (hAFP) in the serum of tumor-bearing mice. hAFP was detected by a chemoluminescent magnetic immunoassay and analyzed in an ARCHITECT optical system. Alternatively, tumor development was monitored by detection of luciferase photon emission, using a Xenogen (IVIS 100 series; Caliper LifeScience, Hopkinton, MA, USA) living image system. Anesthetized mice were injected intraperitoneally with $3 \mathrm{mg}$ of D-Luciferin (Promega) diluted in saline, $5 \mathrm{~min}$ before light caption. The image acquisition time was in the range of 1-2 min. Data analyses were performed using the Living Image Igor Pro (Xenogen) software coupled to the IVIS system. Photon counts were calculated for each mouse using a circular region of interest.

\section{Drugs and Treatment Schedules Used for In-vivo Therapies}

CTX (Endoxan; Baxter Oncology GmbH, Halle/Westfalen, Germany) was reconstituted following manufacturer's instructions to a stock of $20 \mathrm{mg} / \mathrm{kg}$. LDM-CTX was given ad libitum, through the drinking water to administer an approximate dose of $20 \mathrm{mg} / \mathrm{kg}$ per day, based on the estimated daily consumption of $2 \mathrm{ml}$ for a 20 -g mouse, as previously described. ${ }^{5}$ The CTX solution was changed twice a week. The MTD-CTX schedule was a 21-day cycle of $150 \mathrm{mg} / \mathrm{kg}$ CTX, administered i.p. once every other day over 6 days, followed by 2 weeks of rest. G6.31, kindly supplied by Genentech (South San Francisco, CA, USA) is a neutralizing monoclonal anti-VEGF antibody that exhibits cross-species reactivity and was injected i.p. at a dose of $0.75 \mathrm{mg} / \mathrm{kg}$ in $0.1 \mathrm{ml}$ twice a week. Treatment was initiated at day 10 post cell injection and was given for a total of 15 doses over the 50-day study, as previously described..$^{22}$ Bestatin (Cayman Chem, Ann Arbor, MI, USA) was used at $20 \mathrm{mg} / \mathrm{kg}$, for 14 days of forced oral administration.

\section{Immunohistochemistry}

Tissues were fixed in $10 \%$ buffered formalin, embedded in paraffin, and sectioned ( $5 \mu \mathrm{m}$ in thickness). Slides were stained with H\&E. For immunohistochemistry, slides were processed following standard protocols using antigen retrieval methods. Dilutions of primary antibodies were as follows: 1:400 for anti-PCNA (Clone PC10; Dako); 1:20 for CD31 (Clone SZ31; Dianova); 1:100 for hAFP (Novus Biological, Littleton, CO, USA). Samples were incubated with primary antibodies at $4{ }^{\circ} \mathrm{C}$ overnight. In the case of CD31, incubation with primary antibody was done for $1 \mathrm{~h}$ at RT, followed by an incubation with rabbit anti-rat secondary antibody (Dako) at 1:50 dilution for $30 \mathrm{~min}$ at RT. For visualization of the signals, slides were incubated for $30 \mathrm{~min}$ with the EnVision ${ }^{\mathrm{TM}}$ antirabbit or anti-mouse detection system (Dako). Peroxidase activity was developed with $\mathrm{DAB}$ (3,3'-diaminobenzidine; Dako). For double-staining of hAFP-PCNA and hAFP-CD13 (anti-CD13, Clone 38C12; Abcam), after incubation with the primary antibody (dilution 1:30), slides were incubated with anti-mouse polymer-alkaline phosphatase (AP) secondary antibody MACH2 detection system (Biocare Medical, Concord, CA, USA). In the presence of the AP enzyme, Vulcan Fast Red (Biocare Medical) produces a bright fuchsine-red color. For quantifications, 30 random images $(\times 200)$ per experimental group were captured with a microscope (Leica, Wetzlar, Germany) equipped with the Analysis ${ }^{\mathrm{TM}}$ software. Positive cells were quantified with Image J (Java image processing program developed by NIH, Bethesda, MD, USA). Measurements are given as relative area occupied by positive signals with respect to the reference area.

\section{Immunofluorescence}

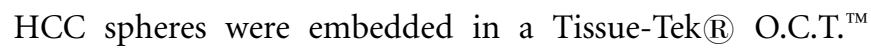
compound (Sakura Finetek, The Netherlands) and stored at $-80^{\circ} \mathrm{C}$. Cryostat sections were used to localize the presence of CD13-positive cells (1:50, Clone 38C12; Abcam) by IF. Briefly, samples on slides were defrosted, fixed with $1 \%$ formaldehyde and permeabilized with $0.1 \%$ Triton-PBS. Unspecific bindings were blocked in 1\% BSA-5\% NSG-0.1\% Triton-PBS. Primary antibody incubation was performed 
overnight at $4{ }^{\circ} \mathrm{C}$. Fluorochrome-labeled secondary antibodies were incubated at room temperature for $30 \mathrm{~min}$. Slides were washed and then incubated with $1 \mu \mathrm{g} / \mathrm{ml}$ Hoechst for $1 \mathrm{~min}$ in darkness. Images were captured with a fluorescent microscope (Zeiss AXIO Imager Z1) equipped with Imaging System V.5.0 software (MetaSystem GmbH, Altlussehem, Germany).

\section{Flow Cytometry}

Flow cytometry characterization was performed according to a previously described procedure. ${ }^{23}$ The following monoclonal antibodies were used: anti-Epithelial Cell Adhesion Molecule (EpCAM), anti-CD90 (Thy-1), anti-ATP Binding Cassette-G2 (ABCG2), anti-CD44, anti-CD49f, anti-CD56 (Neural Cell Adhesion Molecule), anti-CD13, anti-CD146 (all of them from BD Biosciences, San José, CA, USA) and anti-CD133-1 (Miltenyi Biotec, Bergisch Gladbach, Germany), conjugated with fluorescein isothiocyanate (FITC) or phycoerythrin (PE) or PE-Cyanin 7 (PE-Cy7) or allophycocyanin (APC) or APC-Cyanin 7 (APC-Cy7). The threshold fluorescence for negative $v s$ positive cells was set based on the reactivity of appropriate non-specific fluorochrome-conjugated isotypic controls. At least $10^{6}$ cells were finally analyzed using an FACSCanto II equipped with FACSDiva software (BD). Apoptotic cells were identified and excluded from the analysis with 7AAD (Sigma-Aldrich). Cell sorting experiments were performed in a BD-FACSAria cell sorter platform.

To calculate the number of circulating tumor cells (CTC), blood samples were collected by cardiac puncture in $0.5 \mathrm{M}$ EDTA tubes, maintained at room temperature and processed within $6 \mathrm{~h}$ after collection. To avoid unspecific Fc receptormediated antibody binding, samples were incubated with an anti-CD16/32 (BD) antibody for $10 \mathrm{~min}$ at $4{ }^{\circ} \mathrm{C}$. Then, antihuman CD29-PE, which specifically recognizes HCC human cells, and anti-mouse CD45-FITC, a mouse pan-leukocyte antibody, were added and incubated for $15 \mathrm{~min}$ at $4{ }^{\circ} \mathrm{C}$. In all, $5 \mu \mathrm{l}$ 7AAD per $10^{6}$ cells was added for an additional $5 \mathrm{~min}$ to detect apoptotic cells. Red blood cells were then lysed by brief incubation of peripheral blood (PB) samples with erythrocyte lysis buffer (Qiagen, Chatsworth, CA, USA) and washed twice with $0.2 \%$ BSA-0.3\% EDTA-PBS. The threshold fluorescence for negative $v s$ positive cells was set according to the reactivity of rat anti-mouse IgG1-FITC and mouse antihuman IgG1-PE isotypic controls. CTC were defined as mouse CD45- and human CD29 + cells. At least $10^{6}$ cells were analyzed using an FACSCanto II equipped with FACSDiva software.

\section{Imaging of Tumor Angiogenesis}

After confirmation of tumor presence, a solidifying silicone rubber blood pool as contrast agent (Microfil; Flow Tech, Carver, MA, USA) was used to assess tumor vascularization. Briefly, heparin was injected i.p. and silicon rubber was injected into the tail vein. After perfusion and solidification of contrast medium, s.c. or orthotopic liver tumors were removed and scanned with a micro-Computed Axial
Tomography system (micro-CAT II; Siemens Preclinical Solutions, Knoxville, TN, USA) at $75.0 \mathrm{kVp}$ and $250.0 \mathrm{~mA}$. The scans were performed at a resolution of $21 \mathrm{~mm}$. 2D CT images were reconstructed using a standard convolutionback projection procedure with a Shepp-Logan filter using the COBRA program (Exxim Computing Corporation Pleasanton, CA, USA). Images were stored in 3D arrays with a voxel size of $21 \times 21 \times 21 \mathrm{~mm}$. Volumes occupied by vessels were evaluated by Amira 5.2 while vessel dimensions were evaluated with Image J.

\section{RNA Extraction and RT-PCR}

Total RNA was extracted with the QIAamp RNeasy mini extraction kit (Qiagen). To generate cDNA, $300 \mathrm{ng}$ of total RNA was reverse transcribed with $200 \mathrm{U}^{\text {SuperScript }}{ }^{\mathrm{TM}}$ II Reverse Transcriptase into cDNA using $0.5 \mu \mathrm{g}$ oligo(dT) (Invitrogen), $0.05 \mathrm{mM}$ DNTPs mix (Applied BioSystem, Forster City, CA, USA), first-strand buffer $5 \times$ (Invitrogen), supplemented with $10 \mathrm{mM}$ DTT (Invitrogen), and $40 \mathrm{U}$ of RNase out. To remove any remaining RNA, cDNA was treated with $2 \mathrm{U}$ of RNAse $\mathrm{H}$ (Invitrogen) and incubated for $20 \mathrm{~min}$ at $37^{\circ} \mathrm{C}$. Real-time RT-PCR analysis was performed to quantify Prom-1 (CD133, HS01009250_m1) and CD13 (HS00952642_m1) with the TaqMan Gene Expression Assays (Applied BioSystems) following manufacturer's instructions.

\section{Statistical Analysis}

Statistical differences between two groups were examined with Student's $t$-test for unpaired data for parametric variables, and the Mann-Whitney $U$-test for unpaired non-parametric variables. Normality was analyzed with the Shapiro-Wilks test. Statistical relationships among variables were determined by Spearman correlation coefficients. Data were analyzed with the SPSS statistical software (version 15.0 for Windows SPSS). $P$-values $<0.05$ were considered as statistically significant. Survival curves were assayed with the Kaplan-Meier test (GraphPad Prism version 5.00).

\section{RESULTS \\ Non-Invasive Monitoring of Orthotopic Primary HCC Growth}

We first tested the ability of different HCC cell lines and human primary cells to produce AFP. In four out of six cell lines and three out of three primary HCC cells, hAFP was detected in the cultured supernatants although in different amounts. In all, $10^{6}$ cells of HepG2 cells produced $1322 \mathrm{ng} / \mathrm{ml}$ of hAFP in supernatant after 4 days in culture. Values for the remaining cells (at the same cell density) were as follows: $300.4 \mathrm{ng} / \mathrm{ml}$ for $\mathrm{HuH}-7,157 \mathrm{ng} / \mathrm{ml}$ for Hep3B, and $6.13 \mathrm{ng} / \mathrm{ml}$ for PLC-PRF/5. In primary cells, HCC1 secreted $133 \mathrm{ng} / \mathrm{ml}$; HCC2, $156 \mathrm{ng} / \mathrm{ml}$; and HCC $3,126 \mathrm{ng} / \mathrm{ml}$.

We then developed an orthotopic model of human HCC in NSG mice in which $10^{5}$ human HCC cells were directly inoculated into the subsera of the liver (Figure 1a). Only male mice were used because, as we previously reported, males 

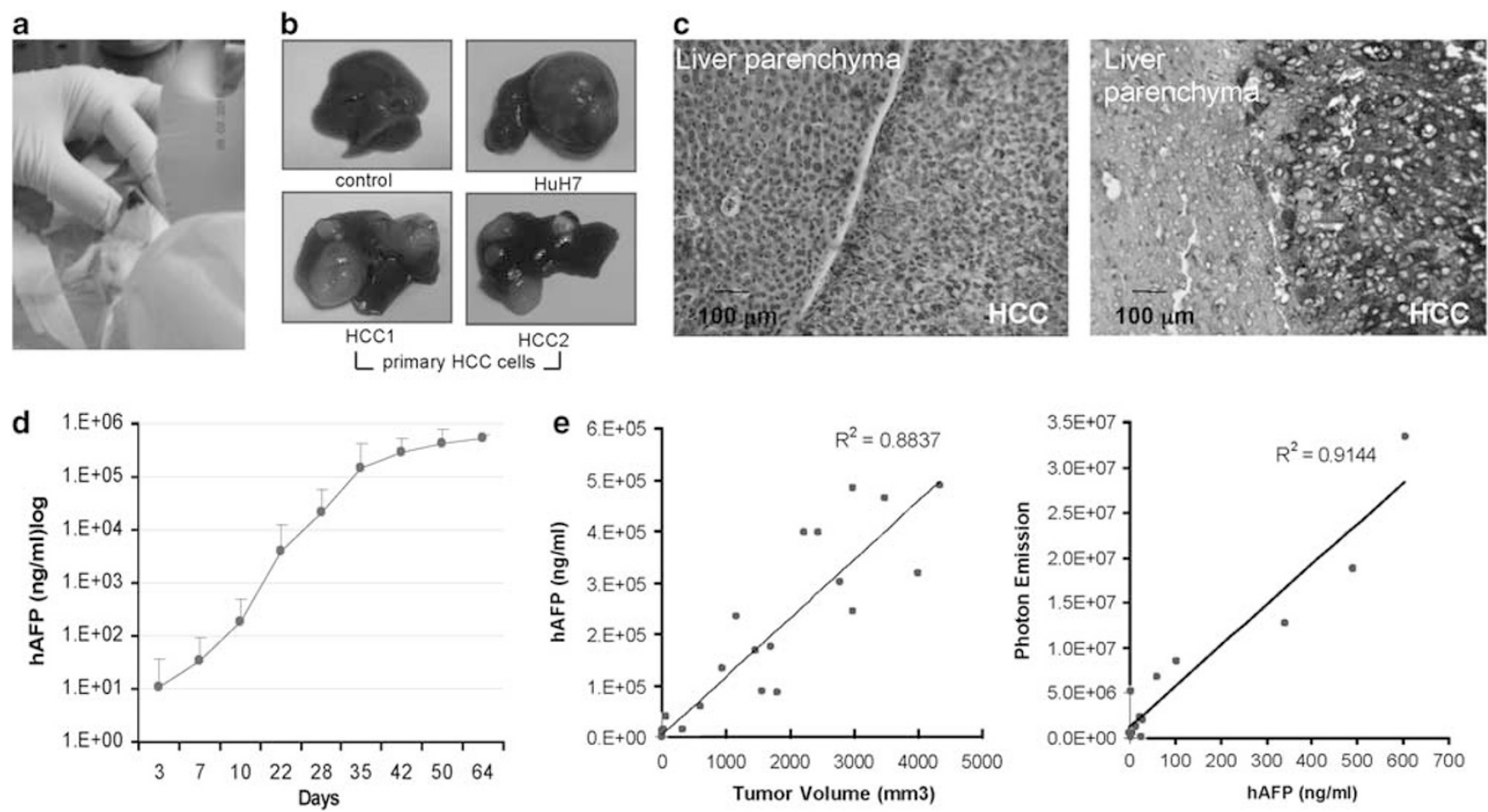

Figure 1 Development of an orthotopic HCC model. (a) $10^{5}$ human HCC cells were implanted directly in the left lobe of the liver of NSG mice. (b) Representative images of the resulting HCC: 2 months after HuH7 tumor cell implantation, a single mass could be seen in the liver, while primary HCC 1 and $\mathrm{HCC} 2$ grew in multiple tumor nodules. (c) hAFP expression in malignant HCC cells by immunohistochemistry but not in liver parenchyma (right panel, $\times 200$ ); H\&E staining, (left panel, $\times 200$ ). (d) hAFP levels in serum samples of HCC-bearing mice. Tumor growth is reflected by hAFP levels, being detectable as soon as day 3 after tumor implantation. (e) Positive correlation between tumor volume and hAFP serum values $\left(R^{2}=0.8837, P=0.001\right.$, left graphic) and between light photon emission and hAFP serum values $\left(R^{2}=0.9144, P=0.001\right.$, right graphic).

were more efficiently engrafted by human HCC than females. ${ }^{23}$ The ability to measure changes in tumor growth is important for deciding when to initiate therapy if treatment of established liver disease is an objective, and to monitor its efficacy. Recording changes in tumor size in this model using traditional methods, such as caliper measurements, is clearly not possible. We decided to take advantage of the property of HCC to secrete hAFP and thus used hAFP detection in the serum as a surrogate marker of relative tumor burden and response to therapy. A week after HCC implantation, hAFP levels were readily detected for all the cell lines and could be monitored weekly to follow tumor progression. No hAFP was detectable in the serum of animals without a tumor or animals that underwent partial hepatectomy, indicating no species crossreactivity in our detection system.

Five mice were implanted with $10^{5}$ cells of each cell line and, as shown in Figure 1b, all tumors grew locally in the liver (in one or several tumor masses, 6-8 weeks later), without signs of macroscopic tumor dissemination in the peritoneum due to leakage during the implant procedure. Eventually, mesenteric lymph-node metastases were detected in all mice after 12 weeks of tumor cell injection. Immunohistochemical analysis for hAFP revealed a strong signal in HCC tumors but not in the liver parenchyma (Figure 1c).
To assess the correlation between levels of serum hAFP and tumor size, we focused our study on one cell line, HuH-7. We first injected $10^{5} \mathrm{HuH}-7$ cells subcutaneously (s.c.) and monitored both hAFP levels and tumor size over time (Figure 1d). As soon as 3 days after injection, hAFP was detectable in the serum and could be weekly monitored by blood sampling from the tail vein. As shown in Figure 1e, we found a statistically significant positive correlation $\left(R^{2}=0.8837, P=\right.$ 0.001 ) between serum hAFP levels and tumor volume.

In addition, using $\mathrm{HuH}-7$ transduced with the retroviral vector TGL (HuH-7-TGL), HCC growth could be monitored in vivo by analyzing light emission. A statistically significant positive correlation $\left(R^{2}=0.9144, P=0.001\right)$ was found between serum hAFP levels and luminometry counts (Figure 1e), as previously described. ${ }^{23}$ Therefore, by combining measurement of hAFP serum levels and luminometry we were able to follow-up orthotopic tumor progression in a noninvasive way.

\section{LDM-CTX Therapy Causes Tumor Regression}

We first compared LDM-CTX therapy with a conventional MTD protocol. As shown in Figure 2a, MTD therapy worked as well as the LDM in initially reducing AFP serum levels. However, MTD-CTX was extremely toxic to NSG mice, resulting in severe weight loss (Supplementary Figure 1), 
a

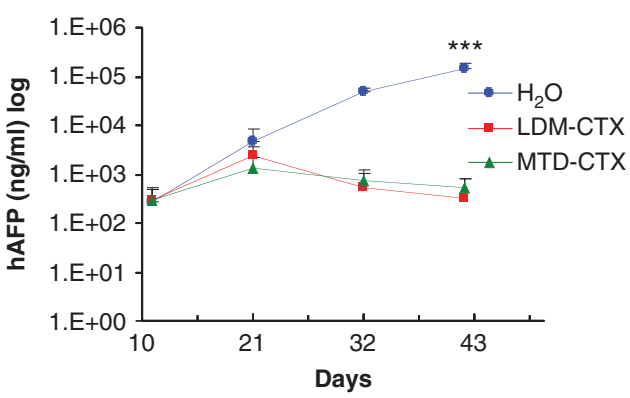

C

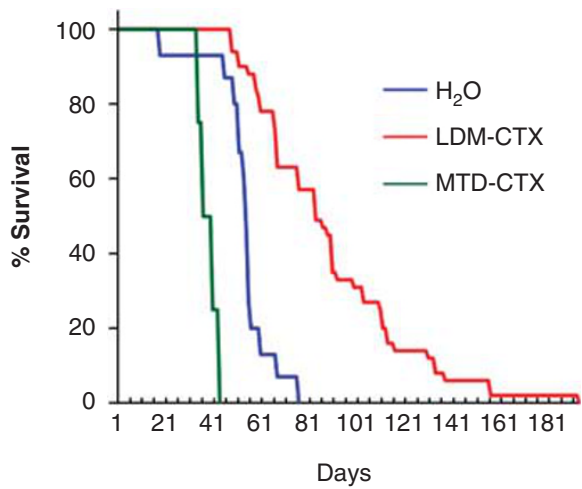

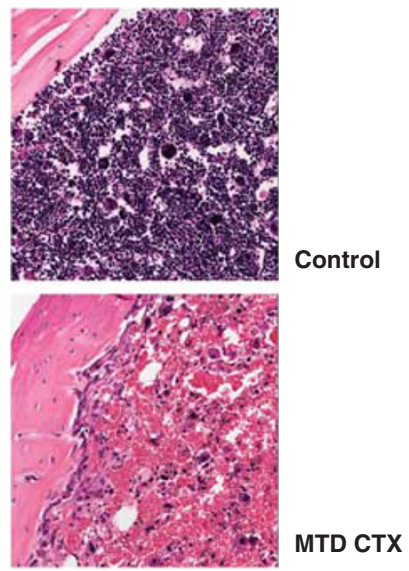

d

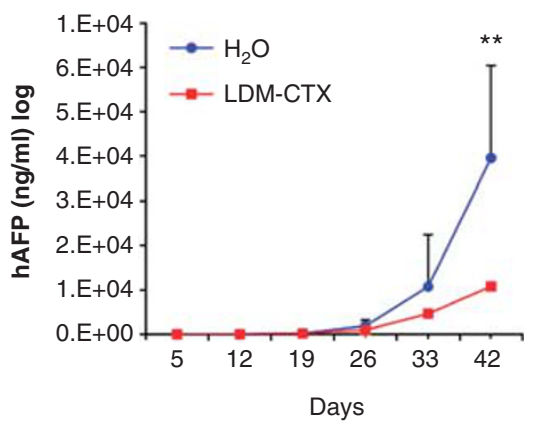

Figure 2 Therapeutic effect of MTD-CTX and LDM-CTX chemotherapy. (a) MTD-CTX and LDM-CTX therapies worked equally well in reducing hAFP serum levels ( ${ }^{* * *} P<0.001 ; n=8$ mice per group, two experiments). (b) MTD-CTX was extremely toxic to NSG mice involving low cellularity of the bone marrow. (c) Kaplan-Meier curves of CTX therapies showing a prolonged survival for LDM-CTX-treated animals when compared with MTD-CTX and control groups $\left(P<0.00001 ; n=8\right.$ mice in MTD-CTX group, $n=50$ mice in LDM-CTX, $n=15$ in the $\mathrm{H}_{2} \mathrm{O}$ control group). (d) LDM-CTX therapy was also effective in slowing primary tumor growth $\left({ }^{*} P<0.01 ; n=6\right.$ mice per group, three experiments).

myeloablation (as demonstrated by low cellularity of the bone marrow; Figure 2b) and low white blood cells counts in $\mathrm{PB}$ (data not shown), and as a consequence, death after about 45 days of treatment. In contrast, no weight loss or other signs of toxicity were recorded in mice treated with LDMCTX for 80 days of continuous therapy using the ad libitum administration, which represents approximately three times the cumulative dose of MTD-CTX therapy.

Comparison of the Kaplan-Meier curves of the control and LDM-CTX-treated mice showed significant differences $(P<0.00001)$ in survival between the two groups (Figure $2 c)$. In addition, hAFP values reflected a decrease in tumor burden in LDM-CTX-administered mice, as compared with controls (Figure 2d).

We then decided to compare the efficacy of LDM-CTX in a prevention-like trial, starting the treatment 3 days after orthotopic cell implantation (hAFP values $0.3 \pm 1.2 \mathrm{ng} / \mathrm{ml}$ ), with LDM-CTX in a treatment-like trial, where administration of the drug was initiated 10 days after cell injection (hAFP value, $100 \pm 13 \mathrm{ng} / \mathrm{ml}$ ). As shown in Figure 3a, early
CTX administration was able to inhibit tumor progression soon after the initiation of the treatment, and at about a month later, hAFP values decreased to $0.67 \pm 0.2 \mathrm{ng} / \mathrm{ml}$. In contrast, when the tumor was well established (hAFP value $100 \pm 13 \mathrm{ng} / \mathrm{ml}$ ), LDM-CTX was less effective and serum levels of hAFP started to decrease after about a month of therapy, reaching values of $50 \pm 16 \mathrm{ng} / \mathrm{ml}$ after 2 months of treatment (Figure $3 \mathrm{~b}$ ). In the prevention trial, control mice bore a localized liver tumor and frequently mesenteric lymph-node metastases at kill (day 32), as detected by luminometry. In contrast, livers of LDM-CTX-treated mice did not show any luminometric signal (at day 52) and only residual hAFP levels were found (Figure $3 \mathrm{c}$ ).

CTC were detected in the PB of HCC-bearing mice by means of flow cytometry. After excluding CD45 + cells, by depicting CD29 + cells we were able to detect a very small population $(0.013-0.015 \%$ of total cells) of CTC-HCC cells in the $\mathrm{PB}$ of tumor-bearing mice, but not in $\mathrm{PB}$ of animals treated with LDM-CTX in a prevention trial (Supplementary Figure 2). The absence of CTC in $\mathrm{PB}$ suggested that 

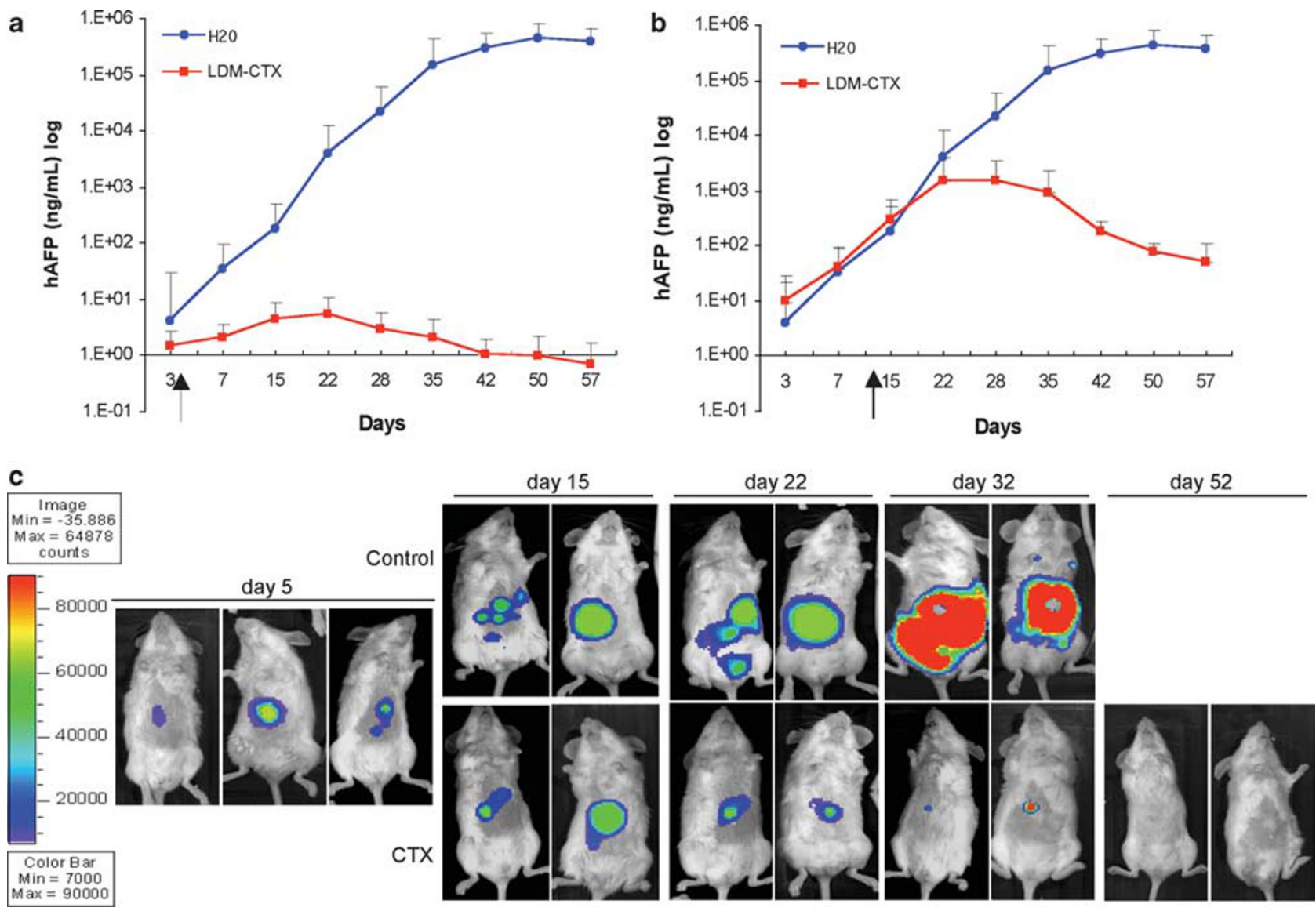

Figure 3 LDM-CTX initiation schedule determines its therapeutic action. (a) Early LDM-CTX administration prevented tumor growth ( $n=13$ mice in LDM-CTX group and $n=10$ mice in the $\mathrm{H}_{2} \mathrm{O}$ control group; three different experiments). (b) Initiation of LDM-CTX treatment when the tumor is well established, delayed tumor progression reaching hAFP values of $50 \pm 16 \mathrm{ng} / \mathrm{ml}$ after 2 months of treatment $(n=15$ mice in LDM-CTX group and $n=10$ mice in control group; three different experiments). (c) Representative luminometric images of mice bearing TGL-HuH7 tumors early treated with LDM-CTX. Light emission shows extensive signal in the abdominal area in the control group by day 32 (day at which animals needed to be killed). In the LDM-CTX treatment group, animals showed a very weak signal by day 32, and by day 52 , no light emission was appreciated.

LDM-CTX might exert an inhibitory effect on HCC dissemination.

As CTX is a pro-drug metabolized by hepatic cytochrome P-450, we next asked whether other types of tumors could be affected by CTX when localized in the liver. We injected $10^{6}$ cells of HT29, a colon carcinoma cell line known to metastasize in the liver. As shown in Figure 4a, LDM-CTX treatment did not affect HT29 tumor growth and metastases. Conversely, when HCC cells were injected s.c., LDM-CTX therapy completely inhibited tumor growth (Figure $4 \mathrm{~b}$ ), suggesting that CTX has a specific effect on HCC biology and development.

To further analyze the LDM-CTX treatment effects on liver tissue, levels of cell proliferation were determined by immunohistochemistry for PCNA. High levels of proliferation were detected not only in the tumor but also in the liver parenchyma of untreated tumor-bearing mice (Figure 4c). In contrast, PCNA staining was restricted to a few dividing cells in the liver parenchyma of mice treated with LDM-CTX and quantification by image analysis showed significant differ- ences $(P=0.03)$ between the two groups (Figure $4 \mathrm{~d})$. To elucidate whether these few dividing cells were tumor resistant, we performed double hAFP/PCNA staining. In livers bearing tumors that received LDM-CTX treatment, hAFP staining was reduced to a few clusters of isolated cells that were always negative for PCNA staining (Figure 5a, lower panels). These data indicated that the PCNA + cells found in the parenchyma were not tumor cells but normal hepatocytes and suggested that clusters of remaining tumor hAFP + /PCNA - cells in LDM-CTX-treated livers were dormant cancer cells. Since, as recently described by Haraguchi et al, ${ }^{16} \mathrm{CD} 13$ could be a possible marker for dormant CSC, we next asked if the hAFP + cell clusters could also be $\mathrm{CD} 13+$. As shown in Figure 5a (right lower panels), the majority of hAFP + cells were also stained for CD13. In tumors of untreated animals, most cancer cells were hAFP + I PCNA + and rare isolated clusters of hAFP + /CD13 + cells could also be seen (Figure 5a, upper panels). Therefore, the hAFP + /CD13 + cell population in LDM-CTX treated 
a

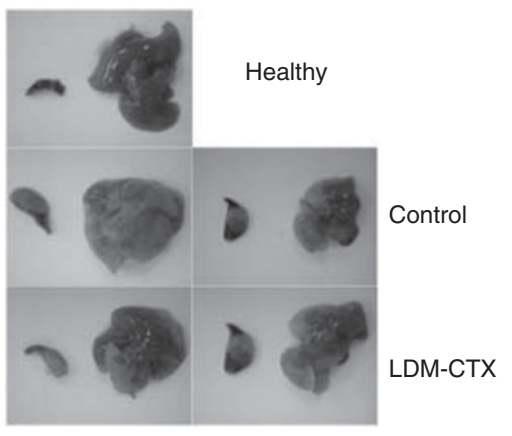

b

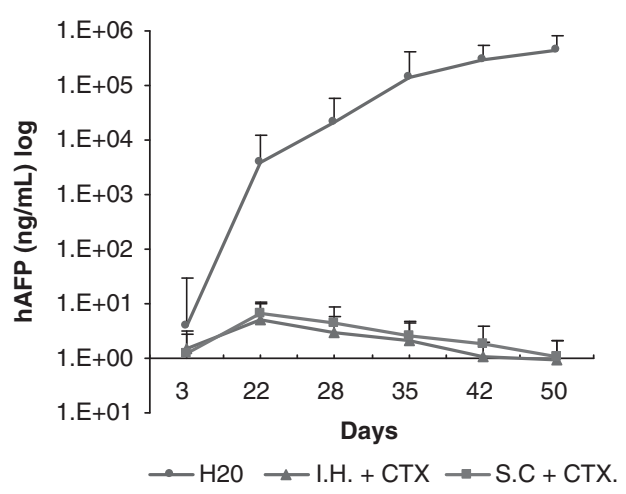

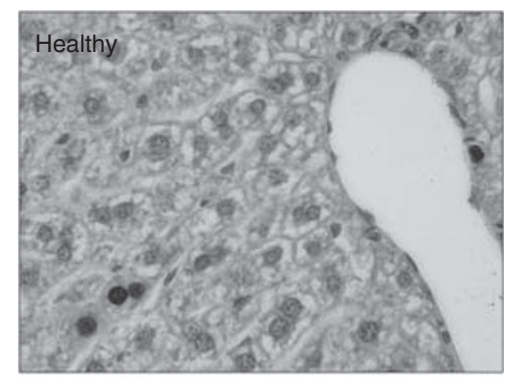
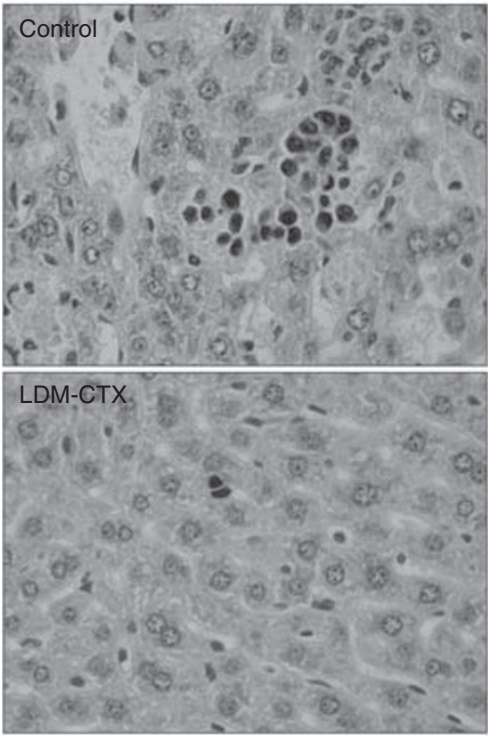

Figure 4 LDM-CTX is specifically active against HCC and inhibits proliferation. (a) Representative images of spleen tumors and liver metastasis of HT29 colon carcinoma cells injected into mice treated with LDM-CTX shows that this chemotherapy does not affect growth and metastases. (b) Tumor growth curve showing that LDM-CTX therapy completely inhibits tumor growth of HCC in subcutaneous (s.c.) implants $\left(n=4\right.$ mice in the $\mathrm{H}_{2} \mathrm{O}$ control group, $n=7$ mice in the s.c. group, $n=7$ mice in the intrahepatic (i.h.) group). (c) PCNA evaluation reveals differences in proliferation rates in the liver parenchyma of tumor-bearing mice. High levels of proliferation were detected in the liver parenchyma of untreated (control) mice, while livers of the LDM-CTX-treated group resemble a healthy liver $(\times 400)$. (d) Quantification of PCNA staining shows significant differences $\left({ }^{*} P=0.03\right)$ between LDM-CTX-treated and control animals, while no differences were found between healthy and LDM-CTX-treated mice.

mice may represent a CSC dormant population that is resistant to treatment.

We were then intrigued by the capability of these small clusters of malignant cells to initiate tumors. To address this issue, a 50-day LDM-CTX treatment was interrupted in a group of six animals presenting $30 \mathrm{ng} / \mathrm{ml}$ of hAFP. A month later, the mean serum hAFP value was $104 \mathrm{ng} / \mathrm{ml}$, thus indicating the tumor relapse (Figure $5 b$ ). Three animals were then killed and examined to evaluate the presence of metastatic foci. Tumor masses were detected only in the liver (not shown), suggesting that the newly formed tumors were probably derived from these clusters of resistant malignant cells. Interestingly, re-administration of LDM-CTX or MTDCTX therapy to the relapsed mice was again effective after 1 week of treatment and reduced hAFP values after 25 days of the second cycle of treatment. Taken together, all these data indicate that LDM-CTX treatment dramatically reduces HCC tumor growth but does not affect cells that present CSC characteristics, such as drug resistance, quiescence, and tumor-initiating capacity.

\section{Antiangiogenic Therapy Synergizes with LDM-CTX and Inhibits HCC Growth}

It is known that metronomic chemotherapy prevents tumor angiogenesis in different tumors. By immunohistochemistry, CD31 staining revealed the presence of numerous tangled vascular structures in tumors and in the surrounding normal parenchyma of untreated animals (Figure 6a). In contrast, vascularization of LDM-CTX-treated livers was reduced and resembled that of the healthy liver parenchyma of untreated mice (Figure 6a). Quantification analysis indicated significant increased levels $(P<0.0001)$ of $\mathrm{CD} 31$ in the liver parenchyma of tumor-bearing animals that was consistently reduced after LDM-CTX treatment (Figure 6a). Tumor vascularization was also analyzed with micro-CT. A noticeable reduction in the group of mice treated with LDM-CTX 

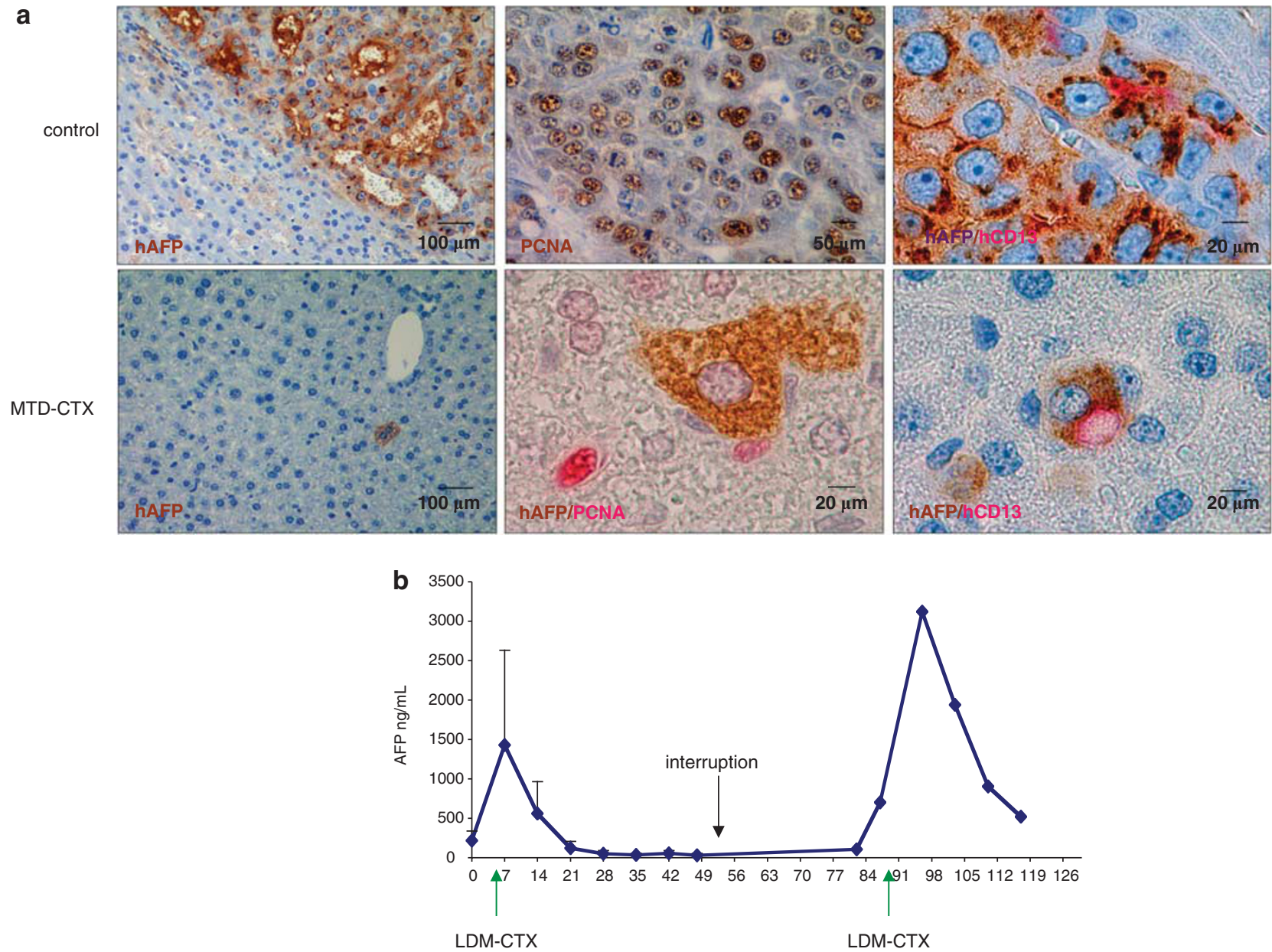

Figure 5 Chemoresistant cell clusters are formed by quiescent, hAFP $+/ C D 13+/ P C N A$ - tumor initiating cells. (a) Upper panels are representative images of hAFP $(\times 200)$; PCNA $(\times 400)$ and hAFP/CD13 $(\times 1000)$ staining of tumor cells. Lower panels show resistant tumor cell clusters that co-express hAFP/CD13 $(\times 1000)$ but not hAFP/PCNA $(\times 1000)$ after administration of LDM-CTX. (b) hAFP levels during LDM-CTX administration. Interruptions in therapy lead to relapse and re-administration of LDM-CTX was again effective to lower hAFP serum levels ( $n=12$ mice, three experiments). LDM-CTX treatment was initiated on day 3 post cell injection.

compared with tumor-bearing control mice was confirmed with this technique (Figure 6b). To further characterize the antiangiogenic effect of the LDM-CTX, we decided to assess the possibility of a combination effect of LDM-CTX with anti-VEGF therapy. As shown in Figure 6c, when using an anti-VEGF treatment, an additional inhibitory effect on tumor growth was observed when mice underwent combination therapy with LDM-CTX, in comparison with LDMCTX alone. However, suppression of LDM-CTX produced tumor relapse after 55-58 days (data not shown) indicating no additional direct effect on tumor-resistant cells.

\section{CTX Targets Hepatic CSC}

We further analyzed resistance to CTX treatment, a typical characteristic of $\mathrm{CSC}^{24}$ Different methods have been proposed for the characterization of liver CSC, such as the development of hepatospheres, colony formation, and self-renewal potential. A sphere formation assay was performed to ascertain whether CTX treatment was able to change the number of CSC. HCC were labeled and then sorted on the basis of their ability to retain the lipophilic dye PKH26 as a consequence of their quiescent nature (Figure 7a). Single PKH26 + cells were then plated and their ability to proliferate and develop spheres was recorded for a week. After this period, we observed that spheres were formed by single PKH26 + cells and by other PKH26- cells, where the dye was diluted out by several cell divisions. This might suggest that a single stem cell can divide asymmetrically in another quiescent stem cell and a proliferating progenitor cell, which in turn, will generate a sphere by successive cell divisions (Figure $7 \mathrm{~b}$ ). To verify the self-renewal property of this putative stem cell, we obtained a second generation by mechanical disaggregation of the first generation of spheres. As shown in Figure 7c, the number of cells 
a
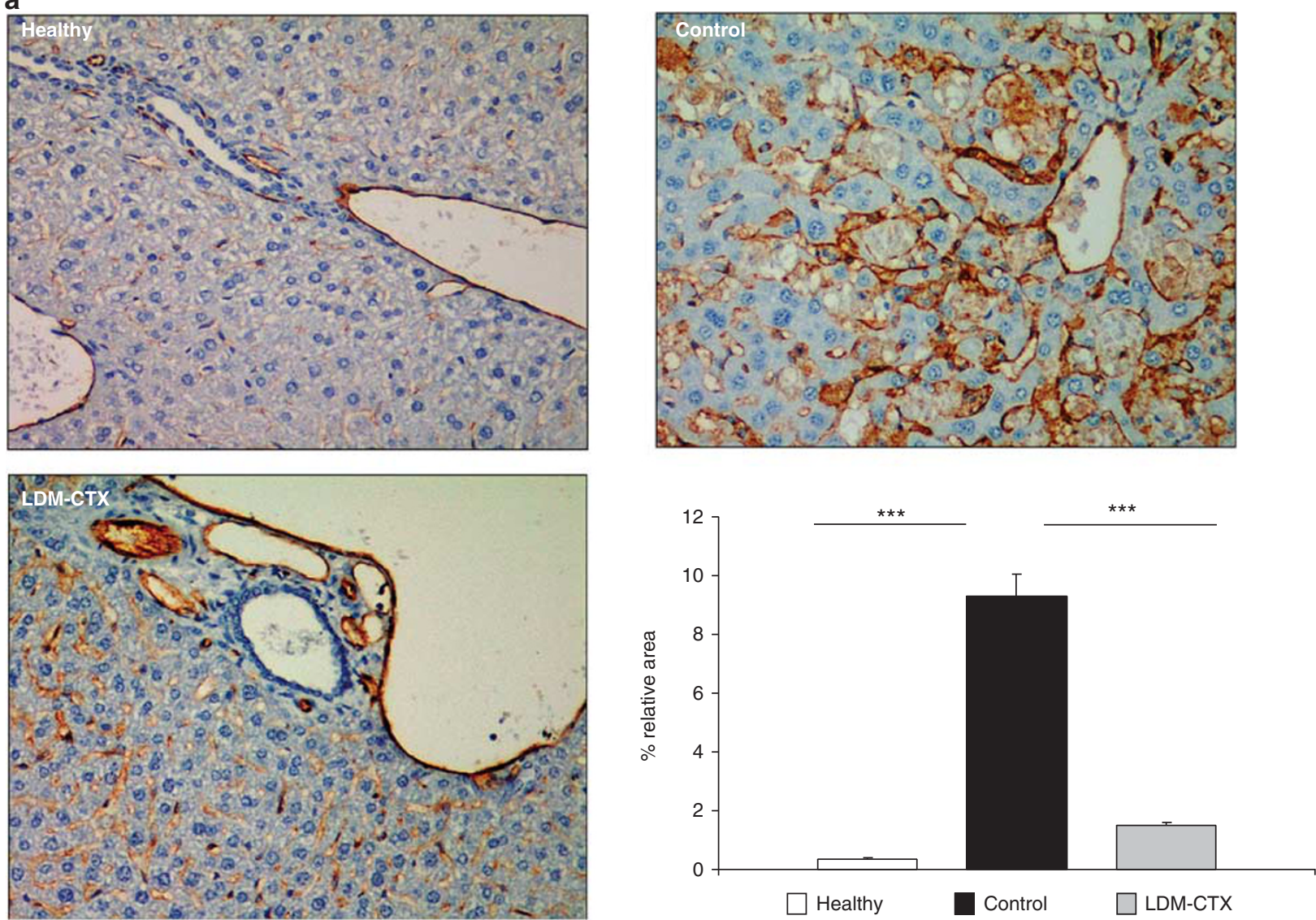

b

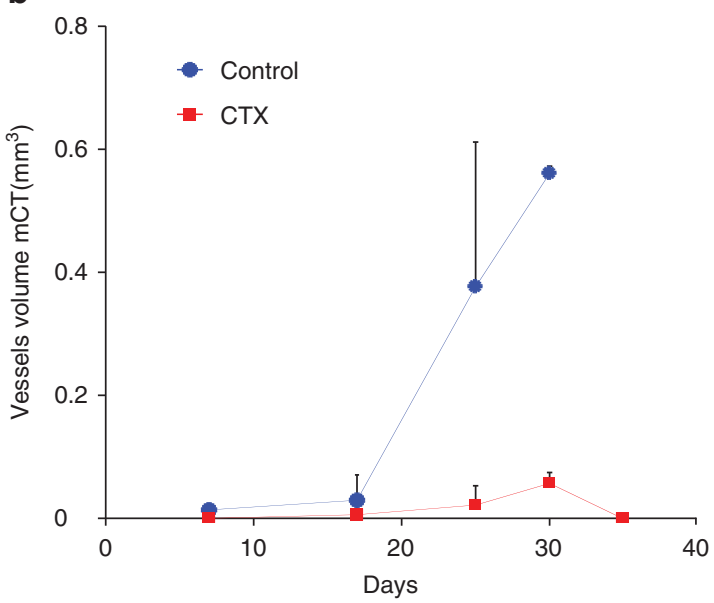

C

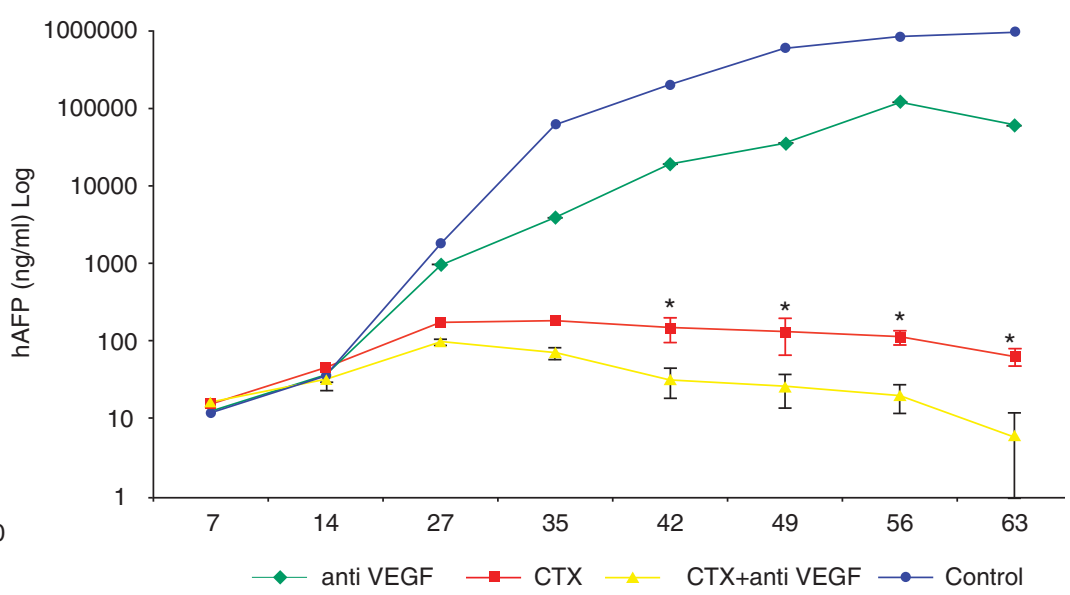

Figure 6 Antiangiogenic action of LDM-CTX and co-administration of anti-VEGF therapy. (a) Vessel density analyzed by CD31 + immunostaining in healthy, control, and LDM-CTX-treated mice $(\times 200)$. Quantification of the vascular index revealed significant differences between LDM-CTX and the control group $(P<0.0001)$, but not between LDM-CTX and the healthy group. (b) Vessel volume measured by micro-CT during tumor progression indicates an increased vascularization in the control group compared with the LDM-CTX-treated group. (c) Combination of LDM-CTX and anti-VEGFA Mab treatment entailed an additional tumor reduction effect as compared with LDM-CTX therapy alone. ${ }^{*} P<0.05 ;{ }^{* *} P<0.001 ; n=10$ mice in the control group, $n=5$ mice in the anti-VEGF groups, $n=8$ in the LMD-CTX and LMD-CTX + anti-VEGF groups; two different experiments.

forming spheres was similar in successive passages, thus demonstrating the stem-cell self-renewal ability of both the HUH7 cell line and primary HCC1 cells.
Using flow cytometry, we analyzed antigen expression of cells growing in either adherent conditions or spheres of previously described stem-cell markers, such as EpCAM, 

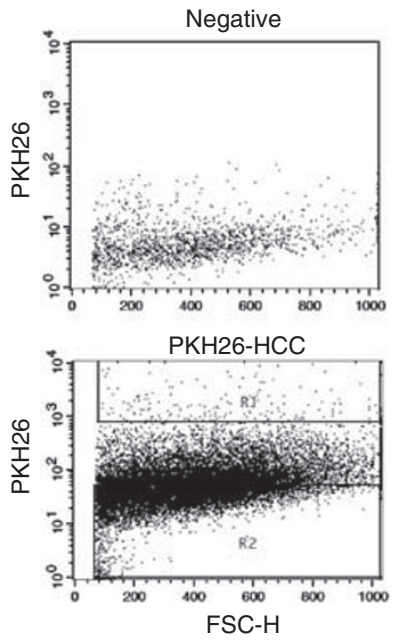

b
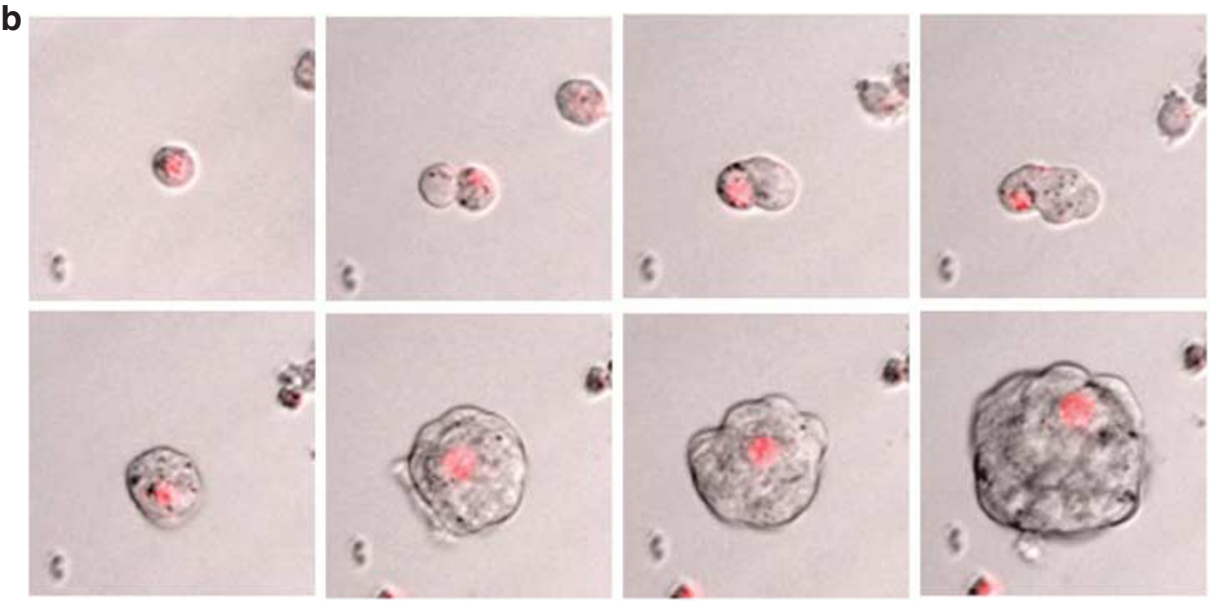

C

\begin{tabular}{cccc}
\hline & 2 & 3 & 4 \\
\hline HCC1 & $1232 \pm 56$ & $1163 \pm 62$ & $1098 \pm 78$ \\
HuH7 & $532 \pm 23$ & $496 \pm 33$ & $502 \pm 25$ \\
\hline
\end{tabular}

d

Flow cytometry antigen expression (\%)

\begin{tabular}{|c|c|c|c|c|c|c|c|c|}
\hline & EpCAM & CD $49 f$ & CD133 & CD44 & CD56 & CD13 & Thy-1 & ABCG2 \\
\hline HCC-1 & 90 & 100 & $<1$ & 33 & 5 & 60 & $<1$ & 60 \\
\hline HCC-2 & 14 & 40 & 3 & 1 & 4 & 35 & 30 & 50 \\
\hline $\mathrm{HuH7}$ & 12 & 96 & 80 & 1.5 & 03 & 97 & $<1$ & $<1$ \\
\hline HCC-1 spheres & 45 & 71 & 5 & 21 & 5 & 67 & $<1$ & 20 \\
\hline HuH7 spheres & 30 & 87 & 92 & 2.3 & 2.3 & 95 & $<1$ & $<1$ \\
\hline
\end{tabular}

Figure 7 Hepatospheres formation and properties. (a) Sorting parameters of PKH26 ${ }^{\text {high }}$ HCC cells in R1. (b) Representative sequential images by time-lapse microscopy of hepatosphere formation from a single PKH $26^{\text {high }} \mathrm{HCC}$ cell of two different experiments. (c) Quantification of number of cells that formed a hepatosphere at different passages ( 3 wells/condition of four different experiments). Maintenance of cell numbers in successive sphere generations suggests self-renewal properties of the initiating cells. (d) Flow cytometry antigen expression of HCC primary cells (HCC-1/2/3) and HuH-7 in adherent and non-adherent culture conditions (spheres).

CD49f, CD133, CD44, CD56, CD13, Thy-1, and ABCG2. As shown in Figure $7 \mathrm{~d}$, there was a large heterogeneity in the percentage of cells positive for these markers, showing that there was no single marker that could be considered to exclusively define such population, according to the fact that CSC represent a small rare cell population. Comparison of CD133 and CD13 gene expression by RT-PCR of cells in adherent and non-adherent conditions revealed a sustained increased expression of both genes in spheres, thus underlining an enrichment of CSC features (Supplementary Figure 3).

To test the effect of LDM-CTX on the CSC population, we performed sphere formation experiments with a metronomic schedule (daily administration) using different doses of the drug. As shown in Figure 8, LDM-CTX caused a dosedependent decrease in sphere number (Figure 8a) and size compared with controls (Figures $8 \mathrm{~b}$ and $\mathrm{c}$ ). Dissociation of control spheres produced $1200 \pm 106$ viable cells, whereas spheres treated with $0.1,0.25$, and $0.5 \mathrm{mM}$ LDM-CTX gave rise to $800 \pm 145,256 \pm 17$, and $123 \pm 42$ viable cells, respectively. No spheres were found at $1 \mathrm{mM}$ LDM-CTX but only a few viable cells remained. Immunofluorescence analysis for CD13 in LDM-CTX spheres revealed an increased proportion of positive cells as compared with control conditions (Figure 8d). This result shows that the CD13 + cell population is particularly resistant to this therapy, which is in agreement with results obtained in tumors. To assess whether the CD13 inhibition can affect tumor growth, we treated HCC tumor-bearing mice with bestatin. Reportedly, bestatin (ubenimex) specifically blocks CD13, which antagonizes with the zinc-binding site of the aminopeptidase N (APN) domain. ${ }^{14}$ hAFP was significantly decreased in the bestatin + LDM-CTX group of mice compared with the LDM-CTX $(P<0.05)$ and the bestatin $(P<0.01)$ groups (Figure 8e). At kill, livers were enzymatically digested and dissociated to seed cells in collagen-coated conditions. Eighteen hours later, cells were recovered and counted. The following results were obtained: $2.2 \times 10^{6} \pm 1362$ cells/mouse in the control group, 
a

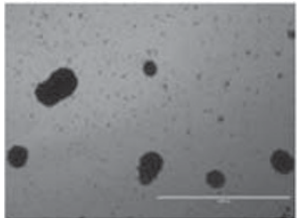

Control

b

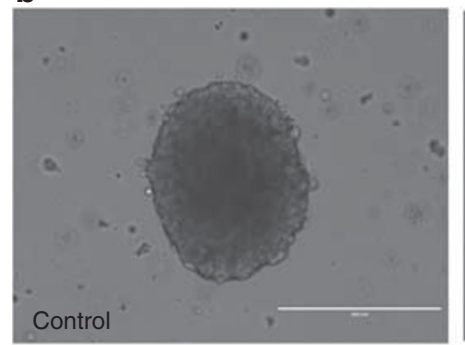

d

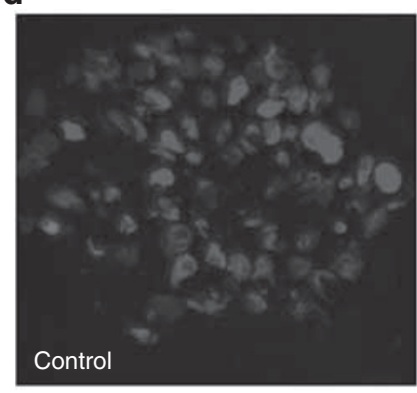

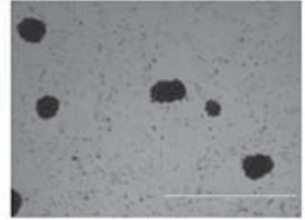

CTX: $0.1 \mathrm{mM}$

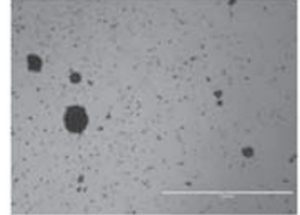

$0.25 \mathrm{mM}$

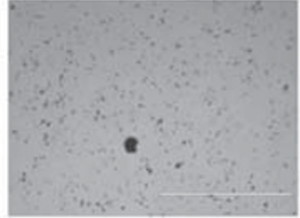

$0.5 \mathrm{mM}$

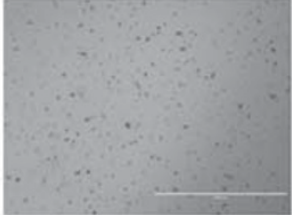

$1 \mathrm{mM}$
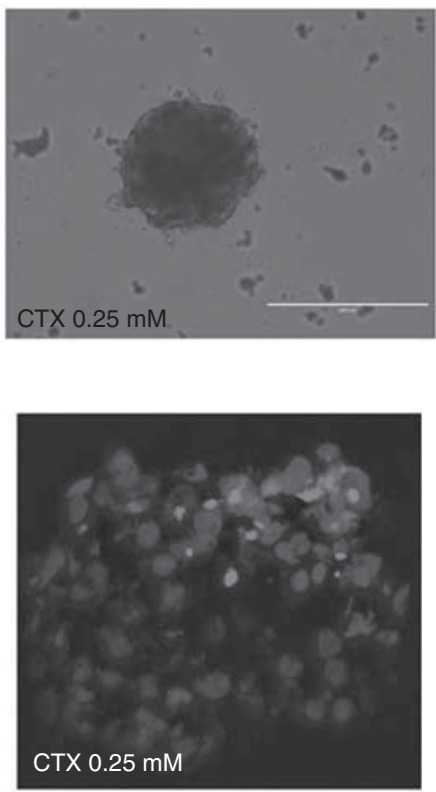

C

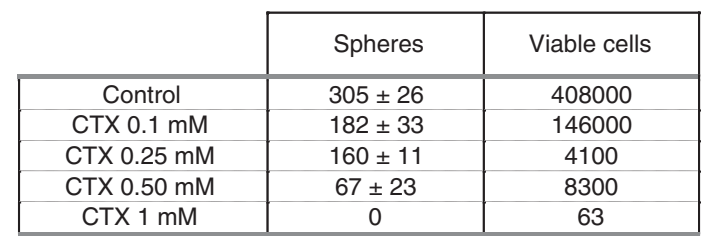

e

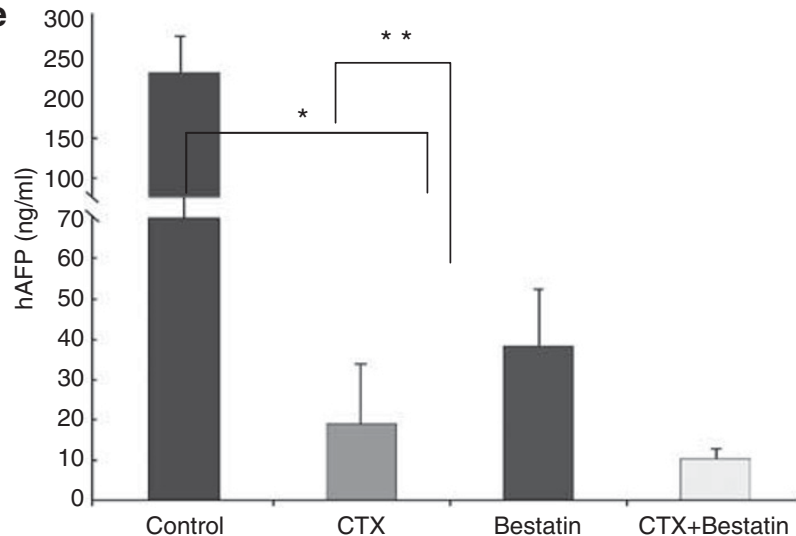

Figure 8 LDM-CTX inhibits hepatospheres formation in vitro. (a) Representative images of inhibitory dose effect of LDM-CTX treatment on hepatosphere formation (4 wells/condition of three different experiments). (b) Representative images of hepatospheres size reduction by $0.25 \mathrm{mM}$ LDM-CTX treatment (4 wells/condition of three different experiments). (c) Quantification of sphere number and viable number of cells (upon sphere dissociation) in a six-well plate after a week of treatment with different doses of LDM-CTX (4 wells/condition of three different experiments). (d) CD13 immunofluorescence of representative hepatospheres. Increased labeling was found in LDM-CTX-treated conditions in comparison with almost absence for controls, suggesting enrichment in CSC (2 wells/conditions of two experiments). (e) CD13 inhibition with bestatin elicits cancer regression in vivo. hAFP values of control, LDM-CTX, bestatin and LDM-CTX + bestatin treated mice. Data represent mean \pm s.d., ${ }^{*}<<0.05 ; * * P<0.01$ ( $n=6$ mice in each group of two different experiments).

$9.9 \times 10^{5} \pm 826$ cells/mouse in the bestatin group, $1.7 \times$ $10^{5} \pm 642$ cells/mouse in the LDM-CTX group, and $9.2 \times$ $10^{4} \pm 89$ cells in the bestatin + LDM-CTX group. These data indicate that targeting CD13 reduces tumor growth and, in combination with LDM-CTX, increases the effect of chemotherapy.

\section{DISCUSSION}

HCC is one of the most common malignancies in the world. Surgical resection is a potentially curative therapy, but successive recurrence and metastasis are frequently major obstacles to prolong survival. Systemic treatments for HCC are then needed, but comorbidities of liver dysfunction in many HCC patients hinder their efficacy, which ultimately leads to therapy failure. Mouse xenograft models are useful for the screening of new therapies, anticipating toxicity, predicting drug response, and identifying possible predictive biomarkers. Yet, most HCC preclinical models in mice have involved the use of HCC cell cultured lines implanted ectopically. Subcutaneous injection is frequently used because tumor growth is easy to follow-up, but the resulting tumors are not representative of the HCC disease. In fact, previous studies have reported differences between orthotopic and ectopic subcutaneous implantation in growth, invasiveness, metastasization, angiogenesis, and response to several drugs. ${ }^{25}$ To bypass this problem, some studies manipulated HCC cell lines to express proteins that can be released in the mouse serum as surrogate markers of tumor burden. ${ }^{26} \mathrm{We}$ decided instead to use primary human HCC cells and different HCC cell lines and measure hAFP in mouse serum to follow-up tumor progression for different reasons. First, hAFP is a protein expressed by many HCC cells and there is no need to transfect and select them from a potentially heterogeneous cell population. This is particularly useful 
when dealing with primary cells from patients. In addition, we found hAFP to be a very sensitive marker as it was released into serum as soon as 3 days after tumor implantation, even when the number of cells we injected was 10 times less than in most previous studies (ie, $10^{5}$ cells instead of $10^{6}$ cells). ${ }^{26}$ Moreover, it has been reported that early AFP response predicts treatment efficacy of antiangiogenic systemic therapy in patients with advanced HCC. ${ }^{27}$ We also used luminometry as a way to monitor tumor growth in a non-invasive way and our results show a good correlation with hAFP levels. Therefore, the combination of these two methods may be particularly relevant to monitor orthotopic tumor development with primary cells.

Angiogenesis has a crucial role in facilitating tumor growth and the metastatic process. Therefore, antiangiogenic therapies seem to have a growing importance in the field of antitumor treatment. In particular, HCC is described as a highly vascularized tumor, where VEGF and VEGFR constitute particularly important targets for therapy. Several HCC studies have correlated elevated VEGF levels with the biological behavior of the disease and clinical outcome. Elevated VEGF levels have been detected in the serum and tumor tissues of HCC patients. ${ }^{28,29}$ In addition, high VEGF levels have been associated with more invasive disease, shorter survival time and worse outcomes after surgery and local therapy. ${ }^{30,31}$ Recently, molecular studies of clinical tissues have identified high genomic gains of the VEGF-A gene and the corresponding increased gene expression in a subset of liver cancers. ${ }^{32}$ Sorafenib, an inhibitor of VEGFR and PDGFR, has become the only targeted therapy approved for clinical use in United States and Europe. However, sorafenib has demonstrated a modest efficacy and ongoing trials are testing different drugs involved in specific pathways (EGF and IGF) alone or in combination with chemotherapy. ${ }^{33}$

Metronomic chemotherapy with CTX has been described as another effective antiangiogenic approach for liver cancer. ${ }^{34}$ However, reported effects do not describe complete tumor remission but rather slightly prolonged survival, probably due to the advanced stage of the tumors treated. In fact, comparison of LDM-CTX and MTD-CTX treatment schedules in our study revealed that early treatment with LDM therapy not only causes a significantly prolonged survival, but also induces complete shrinkage of tumor mass. In our HCC model we obtained complete tumor regression by day $50-60$ of treatment, judging from the image analysis results. This impressive therapeutic efficacy is probably due to a direct effect on tumor cells and also to an indirect antiangiogenic activity. Results obtained by both CD31 immunostaining and micro-CT demonstrated the antiangiogenic mechanism elicited by this therapeutic regime. Interestingly, the presence of a tumor mass in the liver alters the vasculature and stimulates hepatocyte proliferation in the surrounding normal liver parenchyma. This aberrant paracrine effect is completely reverted by the LDM-CTX treatment. In addition, LDM-CTX combined with anti-VEGF
mAb treatment showed an improved effect compared with LDM-CTX alone.

A body of work suggests a role of CTC in tumor progression and metastasis and, while a prognostic value has been suggested in several types of tumors, such as breast cancer, ${ }^{35}$ the function of CTC in HCC is still unknown. Here, we present evidence of HCC CTC in the PB of tumor-bearing animals that is reduced by LDM-CTX treatment. Our study corroborates previous research showing that levels of CTC in $\mathrm{PB}$ can be used as surrogate biomarkers for tumor progression and metastatic invasion. ${ }^{36}$

Despite the effectiveness of the LDM-CTX therapy in our HCC model, the presence of low levels of hAFP in mice serum suggested the possibility of the existence of minimal residual disease. This suspicion was confirmed by histological analyses with the identification of a few isolated hAFP + tumor cells. Because previous reports have proposed that CSC may be particularly resistant to chemotherapy, we analyzed the expression of the liver CSC marker CD13 and the proliferation marker PCNA. Recently, it has been shown that CD13 is a marker for CSC in human liver cancer cell lines with dormancy properties. ${ }^{16}$ We found that the cells remaining after LDM-CTX therapy had a hAFP + /CD13 + I PCNA- phenotype, suggesting that they were CSC in a resting state. Tumor dormancy occurs as a result of cell-cycle arrest and can take place at the primary cancer location, in metastatic sites, or as a result of resistance to therapy. ${ }^{37}$ The fact that CSC are in general more resistant to therapy than non-CSC could be related to their low division rates. ${ }^{24}$ Moreover, these 'dormant' CSC were able to re-enter into a growing phase of cell division and regenerate tumor growth in the off-therapy period. Different approaches may be used to address resistance of CSC, and formation of hepatospheres in vitro could be particularly appropriate for studying this issue. $^{38}$

The currently identified markers for CSC have limitations and none of these markers is exclusively expressed by CSC in HCC. ${ }^{39}$ The use of combinations of these markers might be helpful for the identification of CSC. Alternatively, functional assays that test CSC properties can be useful tools to characterize CSC, such as their ability to form hepatospheres in vitro and their chemoresistance, dormancy, and tumor initiating capacity in vivo. Our in vitro assays showed that among different liver CSC markers, only CD13 and CD133 were enriched in hepatospheres, as compared with the original cell population cultured in adherent conditions, for both $\mathrm{HuH7}$ and primary cells. Treatment with increasing doses of LDM-CTX decreased the number and size of hepatospheres. Haraguchi et al ${ }^{16}$ suggested that the expression of CD13 and CD90 appeared to be associated with a more immature stem-like and dormant population. Wang et $a l^{40}$ have shown that OCT4 mediates chemotherapeutic drug resistance in liver cancer cells involving Akt activation and cell proliferation. Another study has demonstrated that CTX reduces Akt levels, thus limiting cell division. ${ }^{41}$ 
Therefore, it is possible that CTX targets liver CSC by inducing a resting hAFP +/CD13 + /PCNA - phenotype instead of a self-diving and cell amplifying phenotype. CTX has also been shown to target breast CD44 +/CD24-/Lin-/ ALDEFLUOR + CSC in xenograft models. ${ }^{42}$ In contrast to docetaxel and cisplatin, CTX caused a $91 \%$ loss of breast CSC in this model. Therefore, the hypothesis that CSC are resistant to all kinds of chemotherapy may be an oversimplification that should be further studied.

Specific CSC-targeted therapies could be used in future studies for a supposedly more efficient therapy. In this regard, CD13 inhibitors have been recently developed ${ }^{43}$ and some of these have been found to be effective anticancer agents. For instance, the novel APN/CD13 inhibitor $24 \mathrm{~F}$ suppresses invasion and angiogenesis of hepatocarcinoma cells ${ }^{44}$ and bestatin (ubenimex), a specific CD13 inhibitor, impairs tumor growth in combination with 5 -FU. ${ }^{45}$ In the present study, we show for the first time that bestatin exerts a potent antitumor growth in HCC. Furthermore, combination of LDM-CTX with bestatin may represent a novel efficacious therapy to reduce HCC growth and relapse as a result of $\mathrm{CD} 13+$ dormant-like cell awakening.

In summary, in this study we set up HCC-xenograft preclinical mouse models from clinical HCC samples and standardized sphere culture conditions for the study of CSC in vitro. We demonstrate the effectiveness (in terms of tumor delay and increased survival) of LDM administration of CTX alone and in combination with anti-VEGF treatment. A residual hAFP +/CD13 + /PCNA - CSC population identified in the liver parenchyma after treatment is responsible for tumor regrowth. Targeting CSC by inhibition of CD13 in combination with LDM-CTX will shed light on how to limit tumor recurrence.

Supplementary Information accompanies the paper on the Laboratory Investigation website (http://www.laboratoryinvestigation.org)

\section{ACKNOWLEDGEMENTS}

We wish to express our gratitude to Dr Rajkumar Savai (Max-Planck Institute for Heart and Lung Research, Bad Nauheim, Germany) for technical advice in the use of Microfil for tumor vascularization, and the Morphology and Image Analysis core facility (CIMA) for analysis of the Computed Axial Tomography imaging. This investigation was supported in part by AIRC, ISS, and Italian Ministry of Health, and by 'UTE project CIMA', and ISCIII-RTICC RD06/0020/0066 grant (to AC).

\section{DISCLOSURE/CONFLICT OF INTEREST}

The authors declare no conflict of interest.

1. Llovet JM, Burroughs A, Bruix J. Hepatocellular carcinoma. Lancet 2003;362:1907-1917.

2. Voiculescu M, Winkler RE, Moscovici M, et al. Chemotherapies and targeted therapies in advanced hepatocellular carcinoma: from laboratory to clinic. J Gastrointestin Liver Dis 2008;17:315-322.

3. Hoshida $Y$, Villanueva A, Kobayashi $M$, et al. Gene expression in fixed tissues and outcome in hepatocellular carcinoma. N Engl J Med 2008;359:1995-2004.
4. Hanahan D, Bergers G, Bergsland E. Less is more, regularly: metronomic dosing of cytotoxic drugs can target tumor angiogenesis in mice. J Clin Invest 2000;105:1045-1047.

5. Bertolini F, Paul S, Mancuso P, et al. Maximum tolerable dose and lowdose metronomic chemotherapy have opposite effects on the mobilization and viability of circulating endothelial progenitor cells. Cancer Res 2003;63:4342-4346.

6. Man S, Bocci G, Francia G, et al. Antitumor effects in mice of low-dose (metronomic) cyclophosphamide administered continuously through the drinking water. Cancer Res 2002;62:2731-2735.

7. Scripture CD, Sparreboom A, Figg WD. Modulation of cytochrome P450 activity: implications for cancer therapy. Lancet Oncol 2005;6:780-789.

8. Pasquier $E$, Kavallaris $M$, Andre N. Metronomic chemotherapy: new rationale for new directions. Nat Rev Clin Oncol 2010;7:455-465.

9. Coghlin C, Murray Gl. Current and emerging concepts in tumour metastasis. J Pathol 2010;222:1-15.

10. Yao Z, Mishra L. Cancer stem cells and hepatocellular carcinoma. Cancer Biol Ther 2009;8:1691-1698.

11. Morrison SJ, Kimble J. Asymmetric and symmetric stem-cell divisions in development and cancer. Nature 2006;441:1068-1074.

12. Morrison SJ, Spradling AC. Stem cells and niches: mechanisms that promote stem cell maintenance throughout life. Cell 2008;132: 598-611.

13. Haraguchi $\mathrm{N}$, Utsunomiya $\mathrm{T}$, Inoue $\mathrm{H}$, et al. Characterization of a side population of cancer cells from human gastrointestinal system. Stem Cells 2006;24:506-513.

14. Zhu Z, Hao X, Yan M, et al. Cancer stem/progenitor cells are highly enriched in CD133+CD44+ population in hepatocellular carcinoma. Int J Cancer 2010;126:2067-2078.

15. Yang ZF, Ho DW, Ng MN, et al. Significance of CD90+ cancer stem cells in human liver cancer. Cancer Cell 2008;13:153-166.

16. Haraguchi $\mathrm{N}$, Ishii $\mathrm{H}$, Mimori $\mathrm{K}$, et al. CD13 is a therapeutic target in human liver cancer stem cells. J Clin Invest 2010;120:3326-3339.

17. Yamashita T, Ji J, Budhu A, et al. EpCAM-positive hepatocellular carcinoma cells are tumor-initiating cells with stem/progenitor cell features. Gastroenterology 2009;136:1012-1024.

18. Folkins $\mathrm{C}$, Man $\mathrm{S}$, Xu $\mathrm{P}$, et al. Anticancer therapies combining antiangiogenic and tumor cell cytotoxic effects reduce the tumor stem-like cell fraction in glioma xenograft tumors. Cancer Res 2007; 67:3560-3564.

19. Colombo F, Baldan F, Mazzucchelli S, et al. Evidence of distinct tumourinitiating cells with different properties in primary human hepatocellular carcinoma. PLoS One 2011;6:e21369.

20. Cicalese A, Bonizzi G, Pasi CE, et al. The tumor suppressor p53 regulates polarity of self-renewing divisions in mammary stem cells. Cell 2009;138:1083-1095.

21. Liang WC, Wu X, Peale FV, et al. Cross-species vascular endothelial growth factor (VEGF)-blocking antibodies completely inhibit the growth of human tumor xenografts and measure the contribution of stromal VEGF. J Biol Chem 2006;281:951-961.

22. Mancuso $P$, Antoniotti $P$, Quarna J, et al. Validation of a standardized method for enumerating circulating endothelial cells and progenitors: flow cytometry and molecular and ultrastructural analyses. Clin Cancer Res 2009;15:267-273.

23. Martin-Padura I, Agliano A, Marighetti $P$, et al. Sex-related efficiency in NSG mouse engraftment. Blood 2010;116:2616-2617.

24. Singh A, Settleman J. EMT, cancer stem cells and drug resistance: an emerging axis of evil in the war on cancer. Oncogene 2010;29: $4741-4751$.

25. Manzotti C, Audisio RA, Pratesi G. Importance of orthotopic implantation for human tumors as model systems: relevance to metastasis and invasion. Clin Exp Metastasis 1993;11:5-14.

26. Tang TC, Man S, Lee CR, et al. Impact of metronomic UFT/ cyclophosphamide chemotherapy and antiangiogenic drug assessed in a new preclinical model of locally advanced orthotopic hepatocellular carcinoma. Neoplasia 2010;12:264-274.

27. Shao YY, Lin ZZ, Hsu C, et al. Early alpha-fetoprotein response predicts treatment efficacy of antiangiogenic systemic therapy in patients with advanced hepatocellular carcinoma. Cancer 2010;116:4590-4596.

28. $\mathrm{Ng}$ IO, Poon RT, Lee JM, et al. Microvessel density, vascular endothelial growth factor and its receptors Flt-1 and Flk-1/KDR in hepatocellular carcinoma. Am J Clin Pathol 2001;116:838-845. 


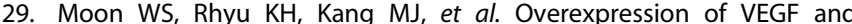
angiopoietin 2: a key to high vascularity of hepatocellular carcinoma? Mod Pathol 2003;16:552-557.

30. Poon RT, Lau C, Pang R, et al. High serum vascular endothelial growth factor levels predict poor prognosis after radiofrequency ablation of hepatocellular carcinoma: importance of tumor biomarker in ablative therapies. Ann Surg Oncol 2007;14:1835-1845.

31. Poon RT, Ho JW, Tong CS, et al. Prognostic significance of serum vascular endothelial growth factor and endostatin in patients with hepatocellular carcinoma. Br J Surg 2004;91:1354-1360.

32. Chiang DY, Villanueva A, Hoshida $Y$, et al. Focal gains of VEGFA and molecular classification of hepatocellular carcinoma. Cancer Res 2008;68:6779-6788

33. Siegel $A B$, Olsen SK, Magun A, et al. Sorafenib: where do we go from here? Hepatology 2010;52:360-369.

34. Kerbel RS, Kamen BA. The anti-angiogenic basis of metronomic chemotherapy. Nat Rev Cancer 2004;4:423-436.

35. Molloy TJ, Bosma AJ, Baumbusch LO, et al. The prognostic significance of tumor cell detection in the peripheral blood versus the bone marrow in 733 early-stage breast cancer patients. Breast Cancer Res 2011;13:R61.

36. $\mathrm{Xu} \mathrm{W}, \mathrm{Cao} \mathrm{L}$, Chen $\mathrm{L}$, et al. Isolation of circulating tumor cells in patients with hepatocellular carcinoma using a novel cell separation strategy. Clin Cancer Res 2011;17:3783-3793.
37. Aguirre-Ghiso JA. Models, mechanisms and clinical evidence for cancer dormancy. Nat Rev Cancer 2007;7:834-846.

38. van Zijl F, Mikulits W. Hepatospheres: three dimensional cell cultures resemble physiological conditions of the liver. World J Hepatol 2010;2:1-7.

39. Liu LL, Fu D, Ma Y, et al. The power and the promise of liver cancer stem cell markers. Stem Cells Dev 2011;20:2023-2030.

40. Wang $X Q$, Ongkeko WM, Chen L, et al. Octamer 4 (Oct4) mediates chemotherapeutic drug resistance in liver cancer cells through a potential Oct4-AKT-ATP-binding cassette G2 pathway. Hepatology 2010;52:528-539.

41. Zeng Q, Yang Z, Gao YJ, et al. Treating triple-negative breast cancer by a combination of rapamycin and cyclophosphamide: an in vivo bioluminescence imaging study. Eur J Cancer 2010:46:1132-1143.

42. Zielske SP, Spalding AC, Lawrence TS. Loss of tumor-initiating cell activity in cyclophosphamide-treated breast xenografts. Transl Oncol 2010;3:149-152.

43. Bauvois B, Dauzonne D. Aminopeptidase-N/CD13 (EC 3.4.11.2) inhibitors: chemistry, biological evaluations, and therapeutic prospects. Med Res Rev 2006;26:88-130.

44. Inagaki $Y$, Tang W, Zhang $L$, et al. Novel aminopeptidase N (APN/CD13) inhibitor 24F can suppress invasion of hepatocellular carcinoma cells as well as angiogenesis. Biosci Trends 2010;4:56-60.

45. Haraguchi N, Ishii $\mathrm{H}$, Mimori $\mathrm{K}$, et al. CD13 is a therapeutic target in human liver cancer stem cells. J Clin Invest 2010;120:3326-3339. 